\title{
Induction of cell-mediated immunity during early stages of infection with intracellular protozoa
}

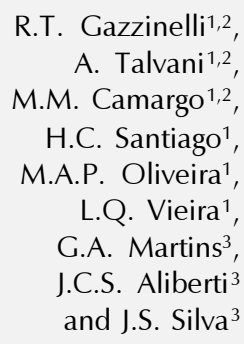

R.T. Gazzinelli1,2, A. Talvani ${ }^{1,2}$ M.M. Camargo ${ }^{1,2}$, H.C. Santiago ${ }^{1}$, M.A.P. Oliveira ${ }^{1}$ L.Q. Vieira ${ }^{1}$ G.A. Martins ${ }^{3}$, J.C.S. Aliberti ${ }^{3}$ and J.S. Silva ${ }^{3}$

\author{
'Departamento de Bioquímica e Imunologia, \\ Universidade Federal de Minas Gerais, Belo Horizonte, MG, Brasil \\ ${ }^{2}$ Centro de Pesquisas René Rachou, Fundação Oswaldo Cruz, \\ Belo Horizonte, MG, Brasil \\ ${ }^{3}$ Departamento de Parasitologia, Microbiologia e Imunologia, \\ Faculdade de Medicina de Ribeirão Preto, Universidade de São Paulo, \\ Ribeirão Preto, SP, Brasil
}

Correspondence

R.T. Gazzinelli

Laboratório de Doença de Chagas Centro de Pesquisas René Rachou FIOCRUZ

Av. Augusto de Lima, 1715

30190-002 Belo Horizonte, MG

Brasil

Fax: 55 (031) 295-3115

E-mail: ritoga@oraculo.lcc.ufmg.br

Presented at the International Meeting on Cytokines, Angra dos Reis, RJ, Brasil, November 24-28, 1996.

Research supported in part by PADCT/CNPq (No. 62.0106/95-6$\mathrm{SBIO}$ ), FAPESP and CNPq (No. 522.056/95-4). R.T. Gazzinelli is the recipient of a Biotechnology Career Fellowship from the Rockefeller Foundation. H.C. Santiago is an undergraduate fellow, M.M. Camargo, A. Talvani, M.A.P. Oliveira, G.A. Martins and J.C.S. Aliberti are graduate fellows, R.T. Gazzinelli, L.Q. Vieira and J.S. Silva are research fellows of CNPq.

Received September 4, 1997 Accepted September 26, 1997

\section{Abstract}

Toxoplasma gondii and Trypanosoma cruzi are intracellular parasites which, as part of their life cycle, induce a potent cell-mediated immunity (CMI) maintaine d by Th1 lymphocytes and IFN- $\gamma$. In both cases, induction of a strong CMI is thought to protect the host against rapid parasite multiplication and consequent pathology and lethality during the acute $p$ hase of infection. However, the parasitic infection is not eliminate $d$ by the immune system and the vertebrate host serves as a parasite reservoir. In contrast, Leishmania sp, which is a slow growing parasite, appears to evade induction of CMI during early stages of infection as a strategy for surviving in a hostile environment (i.e., inside the macrophages which are their obligatory niche in the vertebrate host). Recent reports show that the initiation of IL-12 synthesis by macrophages during these parasitic infections is a key event in regulating CMI and disease outcome. The studies reviewed here indicate that activation/inhibition of distinct signaling pathways and certain macrophage functions by intracellular protozoa are important events in inducing/modulating the immune response of their vertebrate hosts, allowing parasite and host survival and therefore maintaining parasite life cycles.

\section{Introduction}

The parasites Trypanosoma cruzi and Toxoplasma gondii belong to distinct families of the protozoa phylum, the Trypanosomatidae (order Kinetoplastida) and Coccidia (order Apicomplexa), respectively. Although they are phylogenetically distinct, these two species of protozoa have several common features in terms of their biology and their
Key words - Leishmania

- Toxoplasma gondii

- Trypanosoma cruzi

- Macrophages

- Cytokines

- Nitric oxide life cycle in the vertebrate hosts. Both $T$. cruzi and T. gondii infect $a$ wide range of mammals including humans. In addition, these intracellular organisms can infect and replicate inside any kind of nucleated cell of their vertebrate hosts $(1,2)$. As suggested by their host cell specificity in the absence of immunity, these parasites are highly virulent. Thus, during the early phase of infection and before development of specific im- 
munity T. gondii and T. cruzican be found in different tissues and organs, and are normally accompanied by a mononuclear inflammatory reaction in small necrotic foci. With the rapid formation of parasite-specific cell-mediated immunity (CMI), most parasites are cleared from the host tissues, the necrotic foci are regenerated and parasite distribution tends to be more localized. Whereas latent forms of $T$. gondii will localize mainly in the central nervous system (CNS), during chronic infection T. cruzi amastigotes are more easily found in cardiac tissue. In the case of either infection, pathogen-induced CMI maintained by Th1 lymphocytes and IFN- $\gamma$ is thought to be a major event protecting the host against rapid parasite multiplication and consequently against pathology and lethality during the acute $p$ hase of infection $(3,4)$.

IL-12 and IFN- $\gamma$ are thought to be essential cytokines for the establishment of protective Th1-mediated immunity during infection with T. gondii or T. cruzi (3-6). In addition, IFN- $\gamma$ appears to be the key cytokine in activating macrophage effector function, thought to be a major mechanism responsible for controlling T. gondii or T. cruzi replication and parasite dissemination within the vertebrate host tissues during the acute phase of infection (7,8). After the initial phase of disease, acute infection normally evolves to a chronic and asymptomatic stage, and parasite replication is supposed to be controlle $d$ by multiple mechanisms, such as complement fixing antibodies and cytotoxic CD8 ${ }^{+}$lymphocytes, which are maintained by $\mathrm{CD}^{+}$Th1 lymphocytes $(3,5,9-11)$. However, the parasitic infection is not eliminated by the immune system and the vertebrate host will serve as a parasite reservoir, being clearly important for T. gondii or T. cruzi dissemination and maintenance of their life cycle. The importance of $T$ cell-mediated immunity in controlling parasite replication in the chronic stage of infection is clearly observed during reactivation of chronic in- fection in patients with the acquired immunodeficiency syndrome (AIDS) (12-14).

The intracellular parasites of the genus Leishmania use a quite distinct strategy to perpetuate their life cycle. In the first place, in their vertebrate hosts Leishmania parasites are slow-growing parasites that reside and proliferate in a very hostile environment. In contrast to T. cruzi and T. gondii which are facultative macrophage residents, Leishmania sp reside primarily inside macrophages (15). Thus, suppression of macrophage effector functions appears to be $a$ crucial strategy for establishing infection and parasite persistence in the vertebrate host. Several studies indicate that Leishmania may use different strategies to evade induction of macrophage effector functions $(16,17)$. Probably the most powerful strategy is to inhibit the synthesis of IFN- $\gamma$, a cytokine which leads to the activation of macrophage effector functions $(18,19)$. A second strategy would be the inhibition of effector functions in macrophages exposed to IFN- $\gamma(20)$.

In addition to establishing infection, Leishmania parasites must replicate to attain sufficiently high levels and to persist in the vertebrate host tissues in order to favor the encounter with their phlebotomine vector. Therefore, parasites that are able to impair the induction or function of IFN- $\gamma$ would be fovored for transmission. Consistent with this hypothesis, in many vertebrate hosts infection with Leishmania $s p$ is characterized by a period of latency followed by lesion development and parasite proliferation (15). Eventually, after the initial infection, a healing phase follows, which is accompanied by the development of $T$ cellmediated immunity and a decrease in parasite load in vertebrate host tissues. Again both IL-12 and IFN- $\gamma$ have been show $n$ to play an essential role in the healing phase associated with the establishment of protective immunity against different Leishmania species $(21,22)$.

In this review we analyze the studies 
performed in our laboratories and elsewhere, dealing with the initiation of immune responses and effector mechanisms responsible for parasite control during early stages of infection with T. cruzi, T. gondii and Leishmania sp in their vertebrate hosts.

Induction of IL-12 synthesis by macrophages exposed in vitro to live T. gondii or T. cruzi or products derived from these protozoa

It is clear from many studies that, in common with other pathogens, T. gondii and T. cruzi have the capacity to nonspecifically trigger cytokine synthesis by macrophages (6,23-25). We have shown that infection with either live tachyzoites or live trypomastigotes induces cytokine synthesis by different types of macrophages. Our data show that these live parasite forms trigger the synthesis of $a$ wide range of cytokines (i.e., IL$1 \beta$, IL-10, IL-12 and TNF- $\alpha$ ) by inflammatory macrophages in vitro $(23,25)$. It is important to note that the pattern of cytokine expression by macrophages exposed to eitherT. cruzi or T. gondii is highly influenced by IFN- $\gamma(24,26)$ (Figure 1). Production of the same cytokines also occurs in vivo during acute infection with either parasite and these cytokines are important mediators of resistance $(26,27)$.

Interestingly, some particular fractions from these parasites retain the ability to trigger cytokine synthesis by macrophages. A major interest of our research is to identify the molecules of T. gondii and T. cruzi which activate distinct macrophage functions (i.e, cytokine synthesis, nitric oxide release and parasiticidal activity). We have recently shown that glycoconjugates isolate $d$ from $T$. cruzi trypomastigotes are highly enriched for their macrophage-activating potency $(23,28,29)$, as compared to crude parasite extracts. These glycoconjugates are rather complex molecules which possess different chemical structures (i.e., alkylacylglycerol, glycosylphosphatidylinositol (GPI) membrane anchor linked to a mucin-like glycoprotein). Our data also suggest that GPI anchors from these molecules are responsible for triggering the synthesis of different cytokines (including IL-12) by inflammatory macrophages $(23,28,29)$. Studies defining the molecules of $T$. gondii which trigger cytokine synthesis by macrophages are currently in progress. Our preliminary data also indicate the hydrophobic nature of these molecules and that the activity is destroyed by periodic acid oxidation, acid deamination and alkaline hydrolysis $(23,25,30)$. It is important to mention here that in order to induce optimal levels of IL-12 synthesis by macrophages, priming with IFN- $\gamma$ is always required prior to stimulation with glycoconjugates derived from either T. gondii or T. cruzi.

Impairment of IL-12 synthesis by macrophages infected in vitro with Leishmania sp

Interestingly, in vitro infection of macrophages with either L. major or L. donovani does not result in induction of IL-12 synthesis by macrophages, even when the cells are prime $d$ with IFN- $\gamma(18,19,31)$ (Figure 1). In fact, infection with Leishmania leads to complete and selective inhibition of IL-12 synthesis by macrophage host cells activated with different microbial stimuli (19), but has no significant inhibitory effect on the expression of other inducible genes such as IL$1 \alpha$, IL-1 $\beta, T$ NF- $\alpha$, inducible nitric oxide synthase ( $i$ NOS) or IL-10. A possible mechanism for selective inhibition of IL-12 synthesis by macrophages would involve binding to complement receptors, since triggering of complement receptors has been shown to selectively induce IL-12 synthesis by macrophages $(32,33)$. In agreement with this hypothesis are studies showing that the infective stages of Leishmania parasites use the complement receptors for $\mathrm{C} 3$ products in 
Figure 1 - Induction of monokine mRNA expression by inflammatory macrophages exposed to live forms of Toxoplasma gondii, Trypanosoma cruzi and Leishmania major. Thioglycolate-elicited macrophages were incubated in the presence (right panel) or absence (left panel) of IFN- $\gamma$, left uninfected (medium) or infected with tachyzoite, trypomastigote or promastigote forms of $T$. gondii, $T$. cruzi or $L$. major, respectively. After 6 h of incubation, total RNA was extracted from macrophage cultures and expression of the house-keeping gene hypoxanthine phosphoribosyl transferase (HPRT) and monokine (i.e., IL-1ß, TNF- $\alpha$, IL-10 and IL$12-p 40)$ genes was measured by the reverse transcriptase polymerase chain reaction. order to invade macrophages (34). We have also tested the ability of the major L. major surface GPI-anchored molecules from promastigotes as well as amastigotes for their ability to trigger cytokine synthesis by macrophages. Even at concentrations which were two or three logs higher than the optimal doses of T. cruzi trypomastigote- or T. gondii tachyzoite-derived molecules, we were unable to induce cytokine synthesis by inflammatory macrophages using Leishmania-derived glycoconjugates (i.e., lipophosphoglycan (LPG) and glycoinositolphospholipids (GIPLs)) $(28,29,35)$.

Induction of T cell-independent IFN- $\gamma$ synthesis by microbial stimuli

Studies initially performed with Listeria monocytogenes indicated that natural killer
(NK) cells can be triggered to synthesize IFN- $\gamma$ in the absence of $T$ cells (36). This $T$ cell-independent pathway of IFN- $\gamma$ production has been extensively studie $d$ using splenocytes from mice with severe combined immunodeficiency (SCID) (37). In addition to Listeria, a wide variety of intracellular organisms, including T. gondii and T. cruzi, have been shown to stimulate $T$ cell-independent IFN- $\gamma$ synthesis by NK cells $(6,24$, 38,39 ).

The protozoan-induce $d$ IFN- $\gamma$ response was found to be mediate $d$ by NK cells and to be dependent on soluble factors released from macrophage accessory cells $(6,38)$. Follow-up studies with T. gondii and T. cruzi have define $d$ IL-12 as the key cytokine produced by pathogen-activated macrophages and responsible for induction of IFN- $\gamma$ synthesis by NK cells in the absence of T lym-

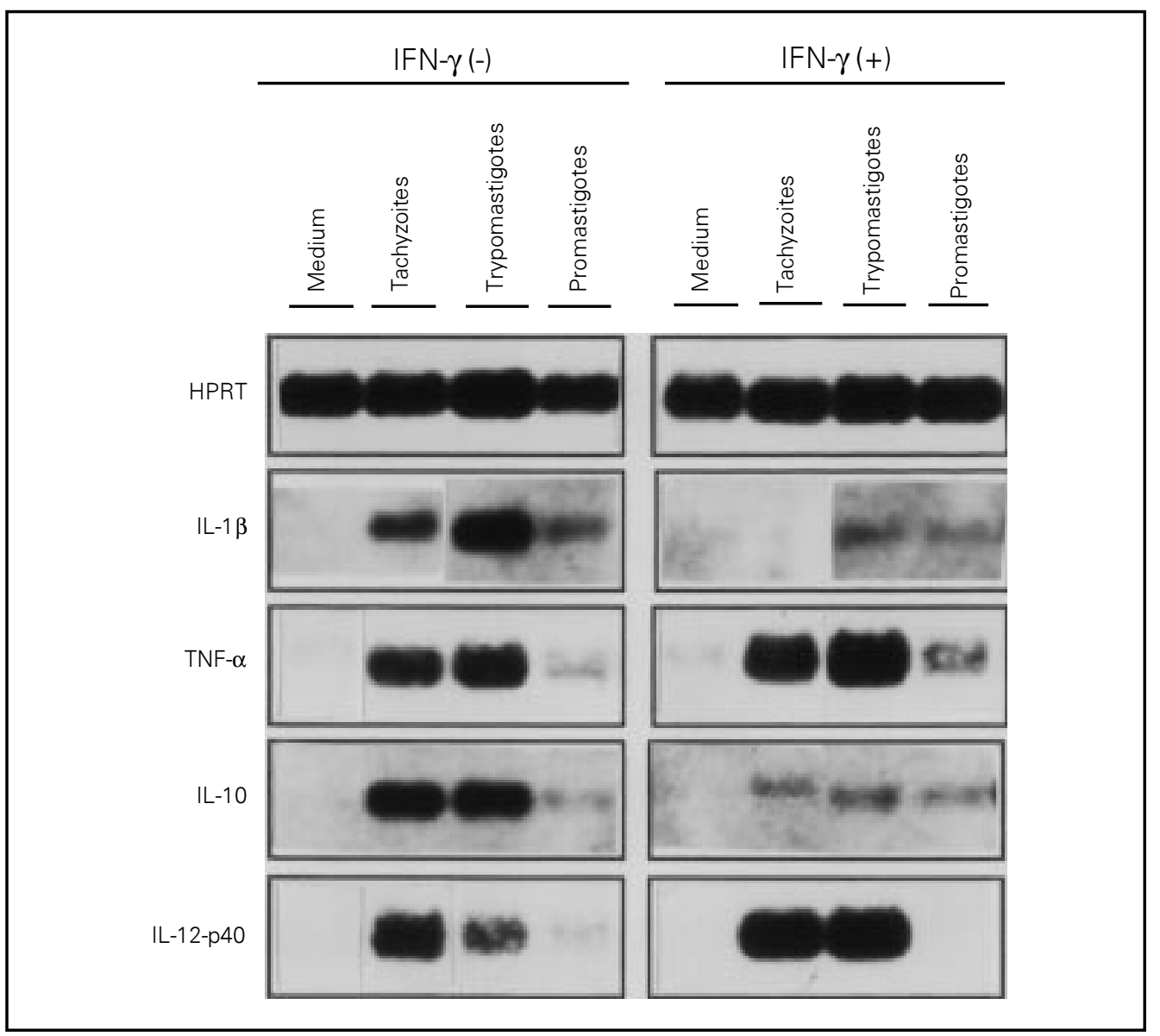


phocytes (Figure 2) $(6,24)$. The importance of this pathway in resistance to infection has also been revealed in studies using T. gondii. Thus, SCID mice treated with anti-IL-12 antibodies have enhanced susceptibility to infection with T. gondii (5).

An important paracrine positive fee $d \mathrm{~b}$ ack loop is observed between NK cells and mac-

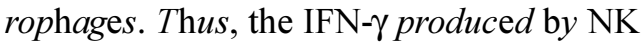
cells is a strong enhancer of IL-12 synthesis by macrophages. However, IFN- $\gamma$ by itself $i s$ not sufficient to trigger IL-12 synthesis, and microbial products appear to be essentially required to initiate IL-12 production by macrophages. Recent studies have also shown that the monokines TNF- $\alpha$, IL-1ß and IL-15 potentiate the effects of IL-12 on inducing IFN- $\gamma$ synthesis by NK cells $(24,38,40,41)$. In contrast, IL-10 and TGF-ß are potent inhibitors of parasite stimulation of IFN- $\gamma$ synthesis by the $T$ cell-independent pathway $(38,39,42)$.

In contrast to T. gondii and T. cruzi, both L. major and L. donovani promastigotes fail to induce IFN- $\gamma$ synthesis by NK cells in the absence of $T$ cells $(43,44)$. Moreover, Scott (45) showed that treatment with anti-CD4 monoclonal antibody (mAb) abolishes in vivo induction of IFN- $\gamma$ by infection with L. major. It is noteworthy that the ability of Leishmania sp to evade (or to inhibit) IL-12 synthesis by macrophages in vitro is consistent with the incompetence of the parasite in triggering IFN- $\gamma$ synthesis by $\mathrm{NK}$ cells in the absence of $T$ cells.

\section{IL-12 bias T cell differentiation} towards the Th1 phenotype

Infection of C57BL/6 or BALB/c mice with L. major has become an important paradigm for the study of in vivo differentiation of Th precursor cells into Th1 or Th2 lymphocytes. Whereas infected C57BL/6 mice develop a Th1-mediated immune response and heal, BALB/c mice develop a Th2 response and eventually succumb to infection with L. major (46). Treatment of BALB/c mice with anti-IL-4 $m \mathrm{Abs}$ switches the differentiation of parasite-specific lymphocytes into the Th1 phenotype and makes the animals resistant to infection with L. major. In contrast, treatment of C57BL/6 mice with ant $i$-IFN- $\gamma$ switches $T$ cell differentiation into the Th2 phenotype leading to enhanced animal susceptibility to infection $(47,48)$. Consistent with these findings is the study showing that adoptive transfer of parasite-specific Th1 cell lines makes BALB/c mice resistant to infection, whereas parasite-specific Th2 cell lines favor susceptibility and uncontrolled lesion development during infection with L. major (49).

Because IFN- $\gamma$ is known to play a major role favoring the differentiation of $T \mathrm{~h}$ cells into the Th1 phenotype $(45,50)$ and IL-12 has been reported to directly promote IFN- $\gamma$ synthesis by Th cells (51,52), the involvement of IL-12 in the generation of Th1 lymphocytes was tested in different systems (5,22,52-55). Most studies indicate that IL12 but not IFN- $\gamma$ acts directly on $T$ cells to enhance priming for IFN- $\gamma$ synthesis, whereas the high levels of IFN- $\gamma$ produced by NK cells and/or T cells exposed to IL-12 clearly favor $T$ cell differentiation towards the Th1

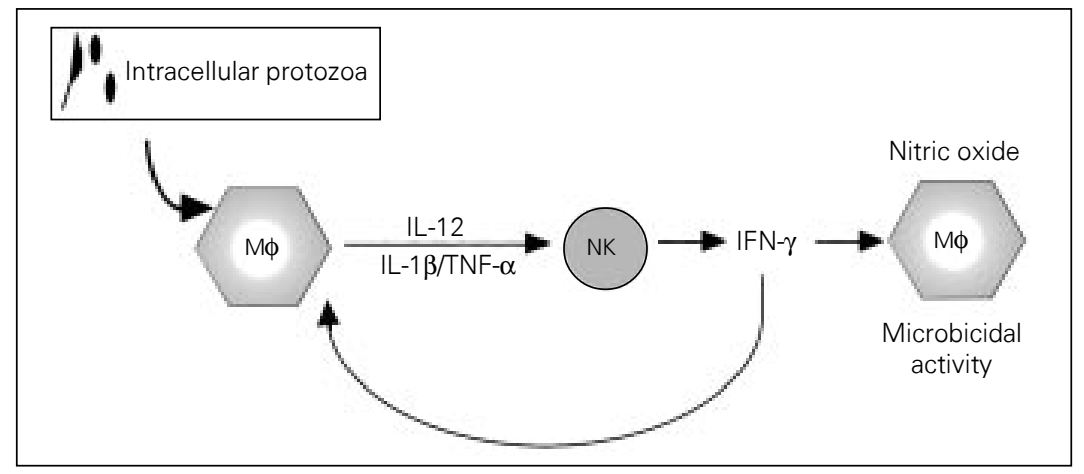

Figure 2 - Induction of the T lymphocyte-independent interferon- $\gamma$ (IFN- $\gamma$ ) pathway by intracellular protozoa. The first target of IL-12 released from macrophages (M $\phi)$ exposed to intracellular protozoan products are natural killer (NK) cells. After exposure to IL-12, NK cells produce high levels of IFN- $\gamma$, even in the absence of T cells. IFN- $\gamma$ derived from NK cells is responsible for the activation of microbicidal effector functions (i.e., nitric oxide synthesis) exhibited by macrophages during early stages of infection. The monokines interleukin-1 13 (IL-1ß) and tumor necrosis factor- $\alpha$ (TNF- $\alpha$ ) potentiate the effects of IL-12 on NK cells and IFN- $\gamma$ enhances the synthesis of IL-12 by macrophages exposed to microbial products. 
phenotype by inhibiting expansion and cytokine synthesis by Th2 lymphocytes (Figure 3). As previously determined (56,57), Th precursor cells will develop into Th2 cells when incubated with IL-4 during primary stimulation with antigen.

Since many microorganisms including the protozoa T. cruziand T. gondii have been shown to trigger IL-12 synthesis by cells of the monocyte/macrophage lineage it was suggested that this event is responsible for Th1 differentiation during different microbial infections. In fact, experiments performe $d$ with naive $\mathrm{CD}^{+} T$ cells derived from transgenic mice expressing only one $\alpha \beta^{+} T$ cell receptor have shown that exposure of antigen-presenting cells (macrophages) to heat-killed L. monocytogenes favored $T$ cell differentiation towards the Th1 phenotype (53). Simultaneous addition of antiIL-12 blocked the effects of heat-killed Listeria on $T$ cell differentiation.

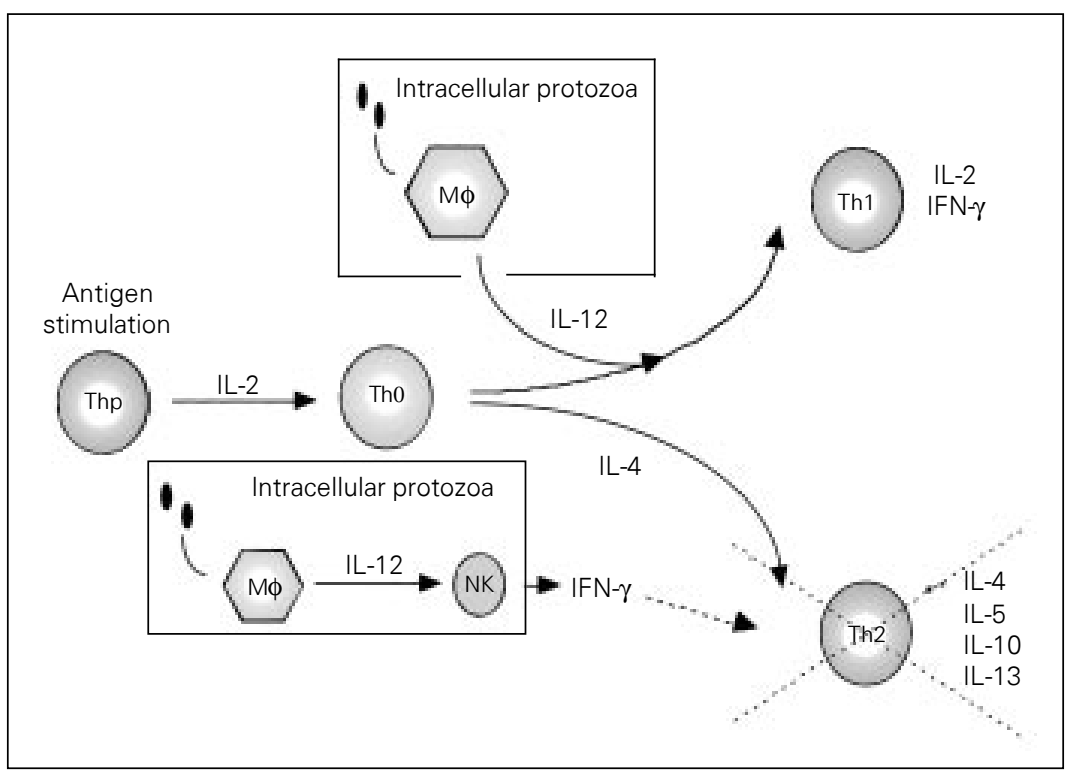

Figure 3 - T helper cell subset selection during infection with intracellular protozoa. Stimulation of Th precursor cells (Thp) by professional antigen-presenting cells such as dendritic cells induces IL-2 synthesis and Thp proliferation and initiates the differentiation of Thp towards the final effector stages, Th1 or Th2, via Th0. Exposure of antigen-stimulated Thp or Th0 stages to IL-12 favors differentiation towards the Th1 phenotype and development of cell-mediated immunity. In contrast, exposure of Thp or Th0 cells to IL-4 favors differentiation towards the Th2 phenotype. IFN- $\gamma$ produced by natural killer (NK) cells or Th1 cells is a potent inhibitor of the development of Th2 lymphocytes, favoring outgrowth of a predominant Th1 subset. M $\phi$, Macrophage.
Experiments were also performed to address the involvement of IL-12 in T cell differentiation in vivo. BALB/c mice infected with L. major develop a strong Th2 response towards the parasite antigen. However, if vaccinate $d$ with parasite extracts in combination with $r$ IL-12 (55), or treate $d$ with $r$ IL-12 during early stages of infection withL. major, BALB/ c mice develop an immune response dominated by Th1 cytokines $(22,58)$.

The studies described above indicate the essential requirement of IL-12 for the inducion of $T$ cell differentiation towards the $T \mathrm{~h} 1$ phenotype. In addition, these studies suggest that to exert its effects on $T$ cell differentiation, IL-12 is needed during the initial encounter of $T$ cells with the antigen. To further analyze the requirement of IL-12 in the maintenance of an already established Th1 response we studie $d$ the role of IL-12 in cytokine synthesis as well as resistance in mice either acutely or chronically infected with $T$. gondii. Our results show that IL-12 synthesis is required for IFN- $\gamma$ production and resistance to T. gondii during acute but not during chronic toxoplasmosis. In contrast, treatment with anti-IFN- $\gamma m \mathrm{Ab}$ enhances susceptibility to this parasite in both stages of infection (5). Altogether these results indicate that IL-12 is required to initiate IFN- $\gamma$ synthesis by lymphocytes, but after a Th1 response is established, IL-12 is no longer required.

Different species of Leishmania induce IL-12 and IFN- $\gamma$ production in vivo

In contrast to the results obtained in in vitro experiments, different studies have indicated that in vivo infection with Leishmania sp does, in fact, trigger the synthesis of IL-12 by macrophages and IFN- $\gamma$ by cells from the lymphocytic lineage and possibly NK cells $(31,55,59,60)$. In addition, it is also known that treatment of resistant mice with neutralizing $m \mathrm{Abs}$ against either IL-12 or 
IFN- $\gamma$ enhances animal susceptibility to infection with different Leishmania species $(21,22,47,61,62)$.

As mentioned in the previous section, parasite-specific Th precursor cells differentiate into the Th2 phenotype in $\mathrm{BALB} /$ c mice and into the Th1 phenotype in C57BL/6 mice, when these mouse strains are infected with L. major. These findings are consistent with the hypothesis that whereas BALB/c mice have a predisposition to developing immune responses dominated by the Th2 phenotype, C57BL/6 mice normally develop immune responses dominated by Th1 lymphocytes (63). Nevertheless, in either mouse strain, infection with $T$. cruzi or T. gondii will lead to the development of Th1 responses $(4,5,64,65$ and our unpublished observations). Taken together with the results described in the sections above, these results indicate that during infection with $T$. gondii or T. cruzi, parasite-induced IL-12 dictates the development of Th precursor lymphocytes into Th1 cells.

During infection with L. major the situation appears to be quite different. Thus, during pregnancy C57BL/6 mice become more susceptible to L. major infection developing the Th2 response instead of the predicted Th1 response in non-pregnant females (66). These results may be explained in part by studies indicating that during pregnancy there is a modulation of Th1 lymphocytes. In contrast, infection with $T$. gondii (35) or treatment with rIL-12 (22,58), which induces systemic levels of IFN- $\gamma$, renders BALB/c mice resistant to infection with L. major, as determined by the development of uncontrolled lesions. At the same time, these animals switch their parasite-specific Th responses towards the Th1 phenotype. Taken together, these findings indicate that during infection with L. major, the status of the host immune system rather than parasite-induced IL-12 and IFN- $\gamma$ is critical in determining the differentiation of Th precursor lymphocytes into Th1 or Th2 effector stages.
In order to compare the ability of Leishmaniasp, T. cruziand T. gondii to induce IL12 and/or IFN- $\gamma$, we performed in vivo or ex vivo experiments with $\mathrm{BALB} / \mathrm{c}$ mice (susceptible to L. major) and C57BL/6 mice (resistant to L. major). When spleen cells were cultured in vitro at several parasite to splenocyte ratios, both T. cruzi and T. gondii triggere $d$ the synthesis of IL-12 and IFN- $\gamma$. In contrast, neither L. major nor L. amazonensis induced detectable levels of either cytokine. Consistent with these observations, we observed that in vitro stimulation with major surface glycoconjugates extracted from $T$. cruzi or T. gondii but not Leishmania sp induced high levels of IL-12 synthesis by murine macrophages (35).

Studies performed in vivo gave us a quite different answer. When parasites were injected intraperitoneally, only T. cruzi and T. gondii induced IL-12 and IFN- $\gamma$ production by splenocytes peaking 5 days postinfection. However, all parasites induced similar levels of IL-12 and IFN- $\gamma$ production by the draining lymph node cells when mice were injected subcutaneously into the hind footpad. Surprisingly, even $\mathrm{BALB} / c$ mice did produce high levels of IL-12 under these conditions. Similar results were obtained when parasites were injected intraperitoneally and IL-12 and IFN- $\gamma$ synthesis was measured in the resident peritoneal cells. Based on these studies, we suggest that, whereas $T$. cruzi and T. gondii trigger systemic cytokine synthesis during acute infection, parasites from the Leishmania genus have a more local effect activating immune cells at the site of infection.

In summary, our data indicate that systemic induction of IL-12 and IFN- $\gamma$ may be required for prompt $T$ cell differentiation into Th1 phenotypes. Alternatively, although infection with L. major might trigger local synthesis of IL-12 and IFN- $\gamma$, the levels are not sufficiently high or produced for long enough periods of time to switch Th precursor cells to differentiate into the Th1 instead 
of the Th2 phenotype in BALB/c mice, which are predisposed to developing immune responses dominated by Th2 cells.

Induction of chemokine synthesis during acute infection with $\mathrm{T}$. gondii or T. cruzi

Chemokines are a group of cytokines related to IL-8 that can be produced by a wide range of cells (e.g., lymphocytes, mast cells, macrophages, fibroblasts, endothelial cells and smooth muscle cells) and are known to have chemotactic as well as activating functions for different types of inflammatory cells of the immune system (67-70). In contrast to the classical chemotactic agents (e.g., C5a, PAF), chemokines are selective attractants that activate distinct leukocyte populations. The hallmark for this family of pro-inflammatory proteins is the conservation of four cysteine residues that are important for the tertiary structure. The chemokines can be divided into two subfamilies depending on whether the first two cysteines are adjacent (C-C chemokines) or not (C-X$\mathrm{C}$ chemokines). In addition, the C-X-C chemokines can be grouped into those containing the ELR motif(e.g., KC and MIP-2) and those lacking the ELR motif (e.g., MIG and IP-10). The ELR motif is common to all C$\mathrm{X}-\mathrm{C}$ chemokines that act on neutrophils. Whereas the major target of the first group of C-X-C chemokines are neutrophils, the chemokines belonging to the latter group of C$\mathrm{X}-\mathrm{C}$ chemokines are major attractants and activators of $T$ lymphocytes and NK cells (67-70). Although, C-C chemokines (e.g., MCP-1, MIP- $1 \alpha$, MIP-1ß and RANTES) are thought to act on monocytes, recent studies indicate that this group of chemokines has a much wider range of biological activity since they can also act on lymphocytes, eosinophils and basophils.

In addition to different microbial products (i.e., LPS, virus dsRNA and Staphylococcus enterotoxin A), the monokines IL-1 and TNF- $\alpha$ are potent inducers of chemokine synthesis in different cell types. In fact, many of the original chemotactic effects attributed to IL-1 and TNF- $\alpha$ were shown later to be mediate $d$ by different chemokines. As shown above, both T. gondii and T. cruzi are potent stimulators of IL-1 and TNF- $\alpha$ synthesis by macrophages. In addition, we have also evaluate $d$ the ability of these parasites to directly induce chemokine synthesis by different types of cells (i.e., macrophages, fibroblasts and endothelial cells). So far, our data indicate that live tachyzoites or live trypomastigotes as well as glycoconjugates isolated from either parasite are able to trigger the synthesis of C-X-C chemokines (i.e., CRG-2 and $\mathrm{KC}$ ) as well as $\mathrm{C}-\mathrm{C}$ chemokines (MIP$1 \alpha$, MIP- $1 \beta$ and RANTES) by inflammatory macrophages (71). It is noteworthy that the cytokine IFN- $\gamma$ has a dual role in the induction of different chemokines. Whereas IFN$\gamma$ is essentially required for induction and/or augmentation of two C-X-C chemokines lacking the ELR motif (i.e., MIG and IP-10), it seems to be a potent inhibitor of certain chemokines such as JE (a C-C chemokine) and $\mathrm{KC}$ ( $a \mathrm{C}-\mathrm{X}-\mathrm{C}$ chemokine). One of the $\mathrm{q} u$ estions raise $d$ by these studies is whether the inducibility and/or inhibitory effects of IFN- $\gamma$ would extend to the other members of the $\mathrm{C}-\mathrm{C}$ and $\mathrm{C}-\mathrm{X}-\mathrm{C}$ chemokines and whether a profile of chemokines could be determined in part by the early synthesis of IFN- $\gamma$ by NK cells.

Our in vivo studies show that acute infection with $T$. gondii is a potent inducer of chemokines MIG and CRG-2 (72). The maximal expression of MIG occurs in different organs/tissues at 7 days of infection and independently of local production of IFN- $\gamma$. Nevertheless, expression of MIG is strictly dependent on IFN- $\gamma$ synthesis and no MIG expression is observed in mice lacking the gene for IFN- $\gamma$ and infected with T. gondii. Whereas macrophages appear to be the major source of MIG in spleens, the major source of this chemokine in other organs has not been defined. 
We have also studied the expression of different chemokines in the cardiac tissue of mice acutely infected with T. cruzi (73). We observed that among the C-X-C chemokines only those induced or potentiated by IFN- $\gamma$ (i.e., CRG-2 or MIG) were significantly increased in the cardiac tissue of mice infected with T. cruzi (data not shown). A slight or undetectable augmentation in expression of other C-X-C chemokines was observed in the cardiac tissue of the same animals. In contrast, expression of all C-C chemokines teste $d$ was augmented in the cardiac tissue of animals acutely infecte $d$ with this protozoan. Interestingly, the chemokine pattern expressed in the host cardiac tissues during the acute $p$ hase of experimental Chagas' disease was closely similar to that expressed by inflammatory macrophages exposed to live trypomastigotes (ortrypomastigote GPI-mucins) plus IFN- $\gamma$. As discussed above, it is possible that the pattern of chemokine expression is determined by cytokines such as IL-1 and TNF- $\alpha$, as well as IFN- $\gamma$, which are produced during infection with T. cruzi. We are currently investigating the effect of in vivo treatment with anti-IFN- $\gamma$ and/or anti$T \mathrm{NF}-\alpha m \mathrm{Abs}$ on chemokine profile and le $u$ kocyte infiltrate in the tissue of animals infected with T. cruzi.

Although there are studies indicating that in vitro infection with Leishmania may trigger the synthesis of certain chemokines in both human and mouse macrophages $(74,75)$, our studies indicate that in contrast to $T$. gondii and T. cruzi parasites, L. major is a very poor inducer of different chemokines by inflammatory macrophages primed or not with IFN- $\gamma$ (our unpublished data).

Role of down-regulatory cytokines (i.e., IL-4, IL-10 and TGF-ß) in modulating induction of cell-mediated immunity and macrophage effector functions

Another important aspect of the strong immune response induced by intracellular protozoa is that under certain conditions, if uncontrolled, it can be the major cause of immunopathology and lethality. Therefore, it seems that the potency of host immune responses triggere $d$ by these parasites has to be tightly regulated, displaying the ability to limit the infection but at the same time lacking pathogenicity. Therefore, the elucidation of the molecular basis involved in the induction of the protective immune response and its regulation may yield important clues for a better understanding of successful long-term interaction between parasites and their vertebrate host.

At the same time that macrophages are responsible for induction of CMI, these cells promote regulation of this response through the production of IL-10 and TGF- $\beta$, which regulates the expression or function of IL-12 and other monokines (Figure 4), as well as through the synthesis of nitric oxide (see next section) which has an antiproliferative effect on cells from the lymphocytic lineage. In addition to regulating monokine synthesis by macrophages (76), IL-10 has been shown to be an important modulator of macrophage effector functions against different parasites $(4,77)$. We have also shown that IL-10 inhib$i$ ts the synthesis of reactive nitrogen intermediates (RNI) by macrophages activated by IFN- $\gamma$ and this inhibitory activity is enhanced by TGF- $\beta$ and IL-4 (78).

In the specific case of infection with $T$. cruzi, IL-10 has been shown to antagonize IFN- $\gamma$ activity rather than IL-12 synthesis (4). Thus, resistant and susceptible mouse strains produce similar levels of IFN- $\gamma$ in response to T. cruzi infection. The levels of IL-10 produced by susceptible animals in response to T. cruzi infection are much higher than those produced in resistant animals. Interestingly, treatment with anti-IL-10 renders susceptible animals more resistant to infection with T. cruzi (79). Similarly, IL-10 KO mice are more resistant to infection with T. cruzi than their wild-type controls (80). 
In recent studies we have assessed the role of IL-10 synthesis in regulating IL-12 and Th1-type cytokine in vivo as well as in establishing the parasite-host equilibrium during acute infection with T. gondii. Our approach was to infect IL-10 KO mice (81) with an avirulent strain of the parasite and to analyze cytokine responses and host resistance to this pathogen. All of the infected IL$10 \mathrm{KO}$ mice died by day 14 postinfection, in contrast to $100 \%$ survival of infected wildtype animals. The IL-10 KO mice infected with $T$. gondii showed a dramatic increase in serum levels of IL-12 and IFN- $\gamma$ as compared to uninfected IL-10 KO or infected wild-type mice. Our results also show that the parasite burden was similar or decreased in the IL-10 KO mice as compared to wildtype animals. In agreement with the RT-PCR results, no evidence of parasite expansion was observed in tissue sections from the IL10 KO mice. Nevertheless, the infected IL$10 \mathrm{KO}$ mice showed clear evidence of enhance $d$ tissue pathology as demonstrated by increased frequency and intensity of cellular infiltration and necrosis in the liver and, to a lesser extent, in the lungs. Taken together, these results suggest that the increased mor-

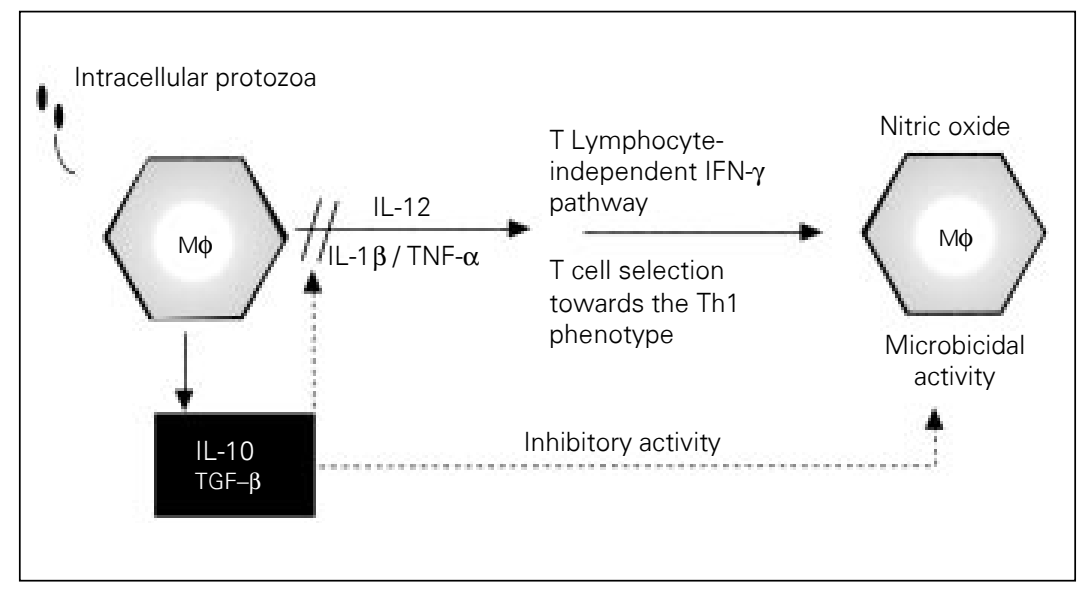

Figure 4 - Down-regulatory role of IL-10 and TGF- $\beta$ in IFN- $\gamma$ synthesis by NK cells and/or T lymphocytes and microbicidal activity by macrophages $(M \phi)$. Macrophages exposed to microbial products will produce IL-10 as well as active TGF- $\beta$ that will modulate the synthesis of IL-12, IL-1 $\beta$ and TNF- $\alpha$ by macrophages, thus inhibiting induction of IFN- $\gamma$ synthesis by NK cells and Th1 lymphocytes. The microbicidal activity (i.e., synthesis of nitric oxide) displayed by IFN- $\gamma$-activated macrophages is also inhibited by IL-10 and TGF- $\beta$. tality of IL-10 KO mice is not due to uncontrolled parasite growth, but to an abnormal pathologic response to infection. The histopathology studies demonstrate $d$ that infected IL-10 KO animals presented pathology similar to that of wild-type animals under continuous treatment with high doses of IL-12 (82). These studies indicate that, if uncontrolled, high levels of IL-12 synthesis during microbial infection can be harmful to the host and, under some conditions, may cause $a$ high incidence of lethality.

$T \mathrm{GF}-\beta$, on its own, is a potent regulator of macrophage effector functions. Thus, mouse treatment with recombinant TGF- $\beta$ makes animals more susceptible to infection with T. cruzi(83), different species of Leishmania $(84,85)$ and $T$. gondii $(42)$. In the case of Leishmania infection, the modulatory role of TGF- $\beta$ appears to be important for parasite replication and lesion development, since high levels of active TGF- $\beta$ are found in the lesions containing Leishmania amastigotes (85).

Finally, IL-4 has been initially shown to block macrophage parasiticidal activity in macrophages activated by IFN- $\gamma(86)$. However, different studies indicate that the major mechanism of action of IL-4 in regulating induction of CMI during L. major infection is to favor the differentiation of parasitespecific Th precursor cells towards the Th2 phenotype (46). Interestingly, IL-4 KO mice are more susceptible to infection with $T$. gondii than wild-type mice. The results obtained by Roberts et al. (87) show that after infection with $T$. gondii a greater mortality is observed in animals lacking IL-4 functional gene. Paradoxally, this enhanced mortality was accompanied by higher levels of IFN- $\gamma$ synthesis and lower tissue parasitism. This study suggests that during acute infection with $T$. gondii induction of IL-4 synthesis may play an important role in regulating an overwhelming parasite-induced Th1 response that can cause host tissue damage and lethality. 
Role of nitric oxide in the control of parasite replication and regulation of cell-mediated immunity induced by Leishmania $\mathrm{sp}, \mathrm{T}$. gondii and T. cruzi

After exposure to IFN- $\gamma$, macrophages exposed to microbial products produce high levels of RNI. In addition to contributing to immune regulation during protozoan infections, the RNI are also important effector molecules responsible for controlling parasite replication by murine macrophages (88).

Our recent in vitro studies have shown that GPI-mucins isolated from trypomastigote membranes are potent inducers of nitric oxide synthesis by IFN- $\gamma$-primed macrophages, even at concentrations as low as $10 \mathrm{ng} /$ $m l$. Consistent with this observation, GPImucins enhanced the killing of different Leishmania species by macrophages. Glycoconjugates isolated from T. gondii tachyzoites have similar activity in inducing nitric oxide synthesis by IFN- $\gamma$-primed macrophages. In contrast, our experiments show that glycolipids (i.e., LPG and GIPLs) obtained from L. major or L. donovani are unable to potentiate the nitric oxide synthesis and/or microbicidal activity displayed by IFN- $\gamma$-primed macrophages, even at concentrations as high as $20 \mu \mathrm{g} / \mathrm{ml}(28,29)$. In studies performe $d$ by Proudfoot and colleagues (20), it was demonstrated that GIPLs extracted from L. major amastigotes inhibit the synthesis of nitric oxide by a murine macrophage cell line. Consistent with these findings are our studies showing that infection of IFN- $\gamma$-primed macrophages with trypomastigotes (or exposure to parasite surface glycoconjugates) leads to macrophage death due to the synthesis of high levels of nitric oxide (Camargo MM and Gazzinelli RT, unpublished observations). Yet infection with L. major has a quite opposite effect, preventing apoptosis in IFN- $\gamma$-activated macrophages (89).

Apoptosis of $\mathrm{CD}^{+} T$ lymphocytes (90) induced by high levels of nitric oxide pro- duced by activated macrophages (91) appears to be an important immunoregulatory mechanism acting during the acute $p$ hase of infection with either T. cruzi or T. gondii $(91,92)$ (Figure 5). The importance of nitric oxide immunoregulatory functions as well as in controlling parasite load is revealed in studies using $i \mathrm{NOS}$ KO mice or animals treated with specific inhibitors for nitric oxide synthesis by $i$ NOS (88). Animals infected with $T$. cruzi and treated with $i$ NOS inhibitors are unable to control parasitemia and mortality can reach $100 \%$ at 25 days postinfection, whereas $100 \%$ of untreated animals survived (7). Similarly, animals infecte $d$ with $T$. gondii and treate $d$ with $i$ NOS inhibitors, or $i$ NOS KO mice infecte $d$ with $T$. gondii, are more susceptible to infection than control animals treated with PBS or wildtype animals infected with $T$. gondii $(93,94)$. The increase in cyst numbers observed in mice infecte $d$ with $T$. gondii and treate $d$ with $i$ NOS inhibitors also results in an intense inflammatory reaction in the CNS (93) indicating that in vivo inhibition of $i$ NOS may also block the immunoregulatory activity of RNI.

Although we were unable to induce nitric oxide synthesis by IFN- $\gamma$-primed macrophages stimulated with LPG or GIPLs, studies performed in our laboratory and elsewhere indicate that infection with Leishmania triggers the synthesis of nitric oxide both in vitro and in vivo $(29,95)$. In agreement with these findings, in vivo treatment with inhibitors of

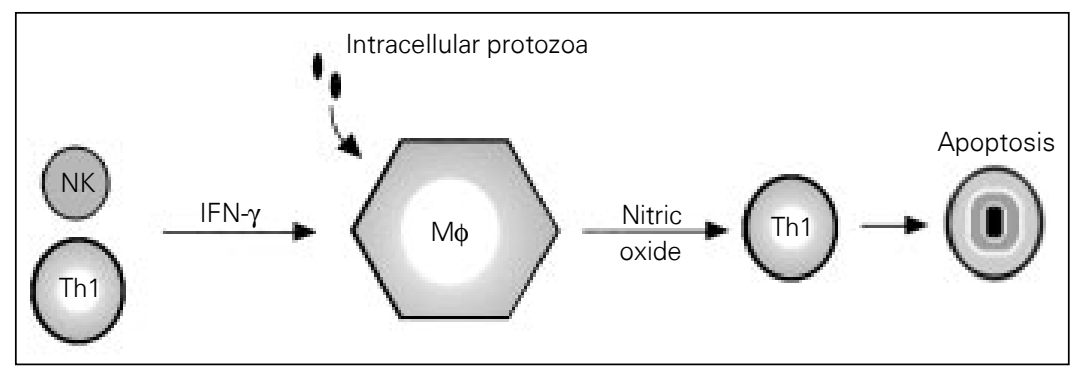

Figure 5 - Antiproliferative effect of nitric oxide on Th1 lymphocytes. Inflammatory macrophages (M $\phi$ ) exposed to products derived from intracellular protozoa as well as IFN- $\gamma$ from NK cells or Th1 lymphocytes produce high levels of nitric oxide. At high concentrations, nitric oxide causes stasis as well as apoptosis of Th1 lymphocytes. 
nitric oxide or the lack of $a$ functional $i$ NOS gene results in enhanced susceptibility to infection with L. major $(96,97)$. Nevertheless, our studies indicate that in vitro (29) and in vivo (Gazzinelli $\mathrm{R} T$, unpublished observations) infection with Leishmania is less potent than infection with either T. cruzi or T. gondii in inducing nitric oxide synthesis.

Activation/inhibition of distinct signaling pathways in macrophages infected with or exposed to intracellular protozoa

Major questions raised from the studies described above are related to the nature of macrophage receptor $(s)$ and characterization of signaling pathways stimulated by T. gondii and T. cruzi products that lead to the induction of cytokine synthesis and activation of distinct macrophage functions. Recent studies indicate that glycoconjugates extracted from T. gondii and GPI anchors extracted from Plasmodium falciparum (98-100) or Trypanosoma brucei (101) induce protein kinase C (PKC) and protein tyrosine kinase activity which is important for the synthesis of cytokines such as IL-1 and TNF- $\alpha$ by macrophages. In addition, these studies suggest that exposure of macrophages to protozoan GPI anchors also induces phosphorylation of IкB, resulting in the release of NF$\kappa \mathrm{B}$, which is essential for the induction of cytokine synthesis and certain macrophage functions.

In contrast, several reports indicate that macrophage infection with Leishmania $s p$ does in fact intercept different signaling pathways such as PKC, leading to the blockage of various macrophage functions $(16,17,20$, 89,102-105). Some of the inhibitory effects on signaling pathways and macrophage functions are mediated by Leishmania glycolip$i d s$ (i.e., LPG and GIPLs) and appear to fovor parasite survival inside macrophages. Further understanding of interferences of
Leishmania parasites in signaling pathways and functions displaye $d$ by macrophages may be instructive as to how modulation of immune responses dictated by macrophages can be achieved.

\section{Conclusions}

A large variety of pathogens and microbial products have been shown to trigger macrophages to produce a diversity of chemoattractant and pro-inflammatory cytokines. Such events appear to be essential in initiating the inflammatory process and determining the nature of the immune responses against invasive organisms. Thus, the initial interaction of intracellular parasites with macrophages may play a major role in determining parasite-host equilibrium and disease outcome during protozoan infections. In this review, we attempte $d$ to analyze the interaction of intracellular protozoa (i.e., $T$. gondii, T. cruzi and Leishmania) with macrophages and the role of this event in the initiation of inflammation and establishment of protective immune responses during infection with such parasites. The tachyzoite forms of T. gondii or trypomastigote and amastigote forms of T. cruzi are strong inducers of the synthesis of different monokines (including IL-12) and chemokines, as well as effector functions by macrophages. We propose that these two intracellular protozoa, which can invade many types of nucleated vertebrate host cells, and therefore are potentially highly virulent, activate macrophages in order to regulate their own numbers, thereby ensuring both host and parasite survival. In contrast, Leishmania parasites are unable to induce a strong cytokine response by macrophages and are less potent in inducing microbicidal activity by macrophages. These findings are consistent with the need for this parasite to evade cell-mediated immunity early in infection, and to persist in the host in high numbers as long as possible, in order to perpetuate its life cycle. 


\section{References}

1. Frenkel JK (1988). Pathophysiology of toxoplasmosis. Parasitology Today, 4: 273-278.

2. Brener Z (1973). Biology of Trypanosoma cruzi. Annual Review of Microbiology, 27: 347-382.

3. Gazzinelli RT, Denkers EY \& Sher A (1993). Host resistance to Toxoplasma gondii: a model for studying the selective induction of cell-mediated immunity by intracellular parasites. Infectious Agents and Disease, 2: 139-149.

4. Silva JS, Morrissey PJ, Grabstein KH, Mohler KM, Anderson D \& Reed SG (1992). Interleukin 10 and interferon- $\gamma$ regulation of experimental Trypanosoma cruzi infection. Journal of Experimental Medicine, 175: 169-174.

5. Gazzinelli RT, Wysocka M, Hayashi S, Denkers EY, Hieny S, Caspar P, Trinchieri G \& Sher A (1994). Parasite-induced IL-12 stimulates early IFN- $\gamma$ synthesis and resistance during acute infection with Toxoplasma gondii. Journal of Immunology, 153: 2533-2543.

6. Aliberti JCS, Cardoso MAG, Martins GA, Gazzinelli RT, Vieira LQ \& Silva JS (1996). IL-12 mediates resistance to Trypanosoma cruzi in mice and is produced by murine macrophages in response to live trypomastigotes. Infection and Immunity, 64: 1961-1967.

7. Vespa GNR, Cunha FO \& Silva JS (1994). Nitric oxide is involved in the control of Trypanosoma cruzi-induced parasitemia and directly kills parasite in vitro. Infection and Immunity, 62: 5177-5182.

8. Scharton-Kersten TM, Wynn TA, Denkers EY, Bala S, Grunvald E, Hieny S, Gazzinelli RT \& Sher A (1996). In the absence of endogenous IFN- $\gamma$, mice develop unimpaired IL-12 responses to Toxoplasma gondii while failing to control acute infection. Journal of Immunology, 157: 4045-4054.

9. Tarleton RL, Koller BH, Latour A \& Postan $M$ (1992). Susceptibility of $ß 2-$-microglobulin-deficient mice to Trypanosoma cruzi infection. Nature, 356: 338-340.

10. Minoprio $P$, Eisen $H$, Joskowicz $M$, Pereira P \& Coutinho A (1987). Suppression of polyclonal antibody production in murine Trypanosoma cruzi-infected mice by treatment with anti-L3T4 antibodies. Journal of Immunology, 139: 545-550.

11. Krettli AU \& Brener Z (1976). Protective effects of specific antibodies in Trypanosoma cruzi infections. Journal of Immunology, 116: 755-760
12. Luft BJ, Brooks RG, Conley FK, McCabe RE \& Remington JS (1984). Toxoplasmic encephalitis in patients with acquired immune response deficiency syndrome. Journal of the American Medical Association, 252: 913-917.

13. Navia BA, Petito CK, Gold JWM, Cho ES, Jordan BD \& Price RW (1986). Cerebral toxoplasmosis complicating the acquired immune deficiency syndrome: clinical and neuropathologic findings in 27 patients. Annals of Neurology, 19: 224-238.

14. Rocha A, Meneses ACO, Silva AM, Ferreira MS, Nishioka SA, Burgarelli NKM, Almeida E, Turcato Jr G, Metze K \& Lopes ER (1994). Pathology of patients with Chagas' disease and acquired immunodeficiency syndrome. American Journal of Tropical Medicine and Hygiene, 50: 261268.

15. Bogdan C, Gessner A, Solbach W \& Rolinghoff M (1996). Invasion, control and persistence of Leishmania parasites. Current Opinion in Immunology, 8: 517-525.

16. Descoteaux A, Matlashewski G \& Turco SJ (1992). Inhibition of macrophage protein kinase C-mediated protein phosphorylation by Leishmania donovani lipophosphoglycan. Journal of Immunology, 149: 3008-3015.

17. Moore KJ, Labrecque S \& Matlashewski G (1993). Alteration of Leishmania donovani infection levels by selective impairment of macrophage signal transduction. Journal of Immunology, 150: 4457-4465.

18. Reiner SL, Zheng SC, Wang ZE, Stowring L \& Locksley RM (1994). Leishmania promastigotes evade interleukin 12 (IL-12) induction by macrophages and stimulate a broad range of cytokines from CD4(+) T cells during initiation of infection. Journal of Experimental Medicine, 179: 447-456.

19. Carrera L, Gazzinelli RT, Badolato R, Hieny S, Müller W, Kühn R \& Sacks DL (1996). Leishmania promastigotes selectively inhibit interleukin 12 induction in bone marrow-derived macrophages from susceptible and resistant mice. Journal of Experimental Medicine, 183: 515-526.

20. Proudfoot $L$, O'Donnell CA \& Liew FY (1995). Glycoinositolphospholipids of Leishmania major inhibit nitric oxide synthesis and reduce leishmanicidal activity in murine macrophages. European Journal of Immunology, 25: 745-750.

21. Belosevic M, Finbloom DS, Van der Meide PH, Slayter MV \& Nacy CA (1989). Administration of monoclonal anti-IFN- $\gamma$ antibodies in vivo abrogates natural resistance of
$\mathrm{C} 3 \mathrm{H} / \mathrm{HeN}$ mice to infection with Leishmania major. Journal of Immunology, 143 266-274.

22. Sypek JP, Chung CL, Mayor SEH, Subramanyam JM, Goldman SJ, Sieburth DS, Wolf SF \& Schaub RG (1993). Resolution of cutaneous leishmaniasis: interleukin 12 initiates a protective T helper type 1 immune response. Journal of Experimental Medicine, 177: 1797-1802.

23. Camargo MM, Almeida IC, Pereira MES, Ferguson MAJ, Travassos LR \& Gazzinelli RT (1997). GPI-anchored mucin-like glycoproteins isolated from Trypanosoma cruzi trypomastigotes initiate the synthesis of pro-inflammatory cytokines by macrophages. Journal of Immunology, 158: 5890-5901

24. Gazzinelli RT, Hieny S, Wynn T, Wolf S \& Sher A (1993). Interleukin 12 is required for the T-lymphocyte independent induction of interferon- $\gamma$ by an intracellular parasite and induces resistance in T-cell-deficient hosts. Proceedings of the National Academy of Sciences, USA, 90: 6115-6119.

25. Grunvald E, Chiaramonte M, Hieny $S$, Wysocka M, Trinchieri G, Vogel SN, Gazzinelli RT \& Sher A (1995). Biochemical characterization and protein kinase $\mathrm{C}$ dependency of monokine inducing activities in Toxoplasma gondii. Infection and Immunity, 64: 2010-2018.

26. Gazzinelli RT, Amichay D, Scharton-Kersten T, Grunvald E, Farber JM \& Sher A (1996). Role of macrophage-derived cytokines in the induction and regulation of cell mediated immunity to Toxoplasma gondii. Current Topics in Microbiology and Immunology, 219: 127-140

27. Gazzinelli RT, Eltoum I, Wynn TA \& Sher A (1993). Acute cerebral toxoplasmosis is induced by in vivo neutralization of TNF- $\alpha$ and correlates with the down-regulated expression of inducible nitric oxide synthase and other markers of macrophage activation. Journal of Immunology, 151: 3672-3681.

28. Gazzinelli RT, Camargo MM, Almeida IC Morita YS, Giraldo M, Acosta-Serrano A, Hieny S, Englund PT, Ferguson MAJ, Travassos LR \& Sher A (1997). Identification and characterization of protozoan products that trigger the synthesis of IL-12 by inflammatory macrophages. Chemical Immunology, 68: 136-152.

29. Camargo MM, Andrade AC, Almeida IC, Travassos LR \& Gazzinelli RT (1997). Glycoconjugates isolated from Trypanosoma 
cruzi but not from Leismania species membranes trigger nitric oxide synthesis as well as microbicidal activity in IFN- $\gamma$ primed macrophages. Journal of Immonology (In press).

30. Gazzinelli RT, Morita YS, Hieny S, Englund PT \& Sher A (1997). Identification and isolation of adjuvant molecules from Toxoplasma gondii tachyzoites. Memórias do Instituto Oswaldo Cruz (In press).

31. Vieira LQ, Hondowicz BD, Afonso LCC, Wysocka M, Trinchieri G \& Scott P (1994). Infection with Leishmania major induces interleukin-12 production in vivo. Immunology Letters, 40: 157-161.

32. Marth T \& Kelsall BL (1997). Regulation of interleukin-12 by complement receptor 3 signalling. Journal of Experimental Medicine (in press)

33. Karp CL, Wysocka M, Wahl LM, Ahearn JM, Cuomo PJ, Sherry B, Trinchieri G \& Griffin DE (1996). Mechanism of suppression of cell-mediated immunity by measles virus. Science, 273: 228-231.

34. Mosser DM \& Edelson PJ (1987). The third component of complement (C3) is responsible for the intracellular survival of Leishmania major. Nature, 327: 329-331.

35. Oliveira MAP, Santiago HC, Lisboa CR, Ceravolo IP, Gazzinelli RT \& Vieira LQ (1996). Comparative studies on the ability of Leishmania sp., Toxoplasma gondii and Trypanosoma cruzi in initiating IL-12 and IFN- $\gamma$ synthesis both in vitro and in vivo. XXI Reunião Anual da Sociedade Brasileira de Imunologia, 1: 139 (Abstract).

36. Bancroft GJ, Sheehan KC, Schreiber RD \& Unanue ER (1989). Tumor necrosis factor is involved in the T-cell-independent pathway of macrophage activation in scid mice. Journal of Immunology, 143: 127130.

37. Bancroft GJ, Schreiber RD \& Unanue ER (1991). Natural immunity: a T-cell-independent pathway of macrophage activation, defined in scid mouse. Immunological Reviews, 124: 5-24.

38. Sher A, Oswald IP, Hieny S \& Gazzinelli RT (1993). Toxoplasma gondii induces a $\mathrm{T}$-independent IFN- $\gamma$ response in natural killer cells that requires both adherent accessory cells and tumor necrosis factor- $\alpha$. Journal of Immunology, 150: 3982-3989.

39. Cardillo F, Voltarelli JC, Reed SG \& Silva JS (1996). Regulation of Trypanosoma cruzi infection in mice by gamma interferon and interleukin-10: the role of NK cells. Infection and Immunity, 64: 128-134.

40. Hunter CA, Chizzonite R \& Remington JS (1995). IL-1ß is required for IL-12 to induce production of IFN- $\gamma$ by NK cells. Journal of Immunology, 155: 4347-4354.
41. Carson WE, Ross ME, Baiocchi RA, Marien MJ, Boiani N, Grabstein K \& Caligiuri M (1995). Endogenous production of interleukin 15 by activated human monocytes is critical for optimal production of interferon- $\gamma$ by natural killer cells in vitro. Journal of Clinical Investigation, 96: 2578-2582

42. Hunter CA, Bermudez L, Beernink $H$, Waegell W \& Remington JS (1995). Transforming growth factor- $\beta$ inhibits interleukin-12-induced production of interferon- $\gamma$ by natural killer cells: a role for transforming growth factor- $\beta$ in the regulation of $T$ cell-mediated resistance to Toxoplasma gondii. European Journal of Immunology, 25: 994-1000.

43. Kaye PM \& Bancroft GJ (1992). Leishmania donovani infection in scid mice: Lack of tissue response and in vivo macrophage activation correlates with failure to trigger natural-killer cell-derived gamma interferon production in vitro. Infection and Immunity, 60: 4335-4342.

44. Varkila K, Chatelain R, Leal LM \& Coffman RL (1993). Reconstitution of C.B.-17 SCID mice with $B A L B / c T$ cells initiates a $T$ helper type-1 response and renders them capable of healing Leishmania major infection. European Journal of Immunology, 23: 1531-1538.

45. Scott $P$ (1991). IFN- $\gamma$ modulates the early development of Th1 and Th2 responses in murine model of cutaneous leishmaniasis. Journal of Immunology, 147: 31493155.

46. Reiner SL \& Locksley RM (1995). The regulation of immunity to Leishmania major. Annual Review of Immunology, 13: 151-177.

47. Heinzel FP, Sadick MD, Holaday BJ \& Locksley RM (1989). Reciprocal expression of interferon-gamma or IL-4 during the resolution or progression of murine leishmaniasis. Evidence for expansion of distinct helper T cell subsets. Journal of Experimental Medicine, 169: 59-72.

48. Sadick MD, Heinzel FP, Holaday BJ, Pu RT, Dawkins RS \& Locksley RM (1990). Cure of murine leishmaniasis with anti-interleukin 4 monoclonal antibody. Evidence for a T cell-dependent, interferon $\gamma$-independent mechanism. Journal of Experimental Medicine, 171: 115-127.

49. Scott $P$, Natovitz $P$, Coffman RL, Pearce E \& Sher A (1988). Immunoregulation of cutaneous leishmaniasis. T cell lines that transfer protective immunity or exacerbation belong to different $T$ helper subsets and respond to distinct parasite antigens. Journal of Experimental Medicine, 168: 1675-1684.
50. Gajewski TF \& Fitch FW (1988). Anti-proliferative effect of IFN- $\gamma$ in immunoregulation. I. IFN- $\gamma$ inhibits the proliferation of Th2 but not Th1 murine helper T lymphocyte clones. Journal of Immunology, 140: 4245-4251.

51. Perussia B, Chan SH, A'Andrea A, Tsuji K, Santoli D, Pospisil M, Young D, Wolf SF \& Trinchieri G (1992). Natural killer (NK) cell stimulatory factor or IL-12 has differential effects on the proliferation of TCR- $\alpha \beta^{+}$, TCR- $\gamma \delta^{+} T$ lymphocytes, and NK cells. Journal of Immunology, 149: 3495-3502.

52. Trinchieri G (1995). Interleukin-12: a pro-inflammatory cytokine with immunoregulatory functions that bridge innate resistance and antigen-specific adaptative immunity. Annual Review of Immunology, 13: 252-276.

53. Hsieh CS, Macatonia SE, Tripp CS, Wolf S, O'Garra A \& Murphy KM (1993). Development of Th1 CD4+ T cells through IL-12 produced by Listeria-induced macrophages. Science, 260: 547-549.

54. Seder RA, Gazzinelli RT, Sher A \& Paul WE (1993). IL-12 acts directly on CD4+ T cells to enhance priming for IFN- $\gamma$ production and diminishes IL-4 inhibition of such priming. Proceedings of the National Academy of Sciences, USA, 90: 1018810192.

55. Afonso LCC, Scharton TM, Vieira LQ, Wysocka M, Trinchieri G \& Scott P (1994). The adjuvant effect of interleukin-12 in a vaccine against Leishmania major. Science, 263: 235-237.

56. Swain $S L$, Weinberg $M$, English $M$ \& Huston G (1990). IL-4 directs the development of Th2-like helper effectors. Journal of Immunology, 145: 3796-3806.

57. Le Gros G, Ben-Sasson SZ, Seder R, Finkelman FD \& Paul WE (1990). Generation of interleukin 4 (IL-4)-producing cells in vivo and in vitro: IL-2 and IL-4 are required for in vitro generation of IL-4-producing cells. Journal of Experimental Medicine, 172: 921-929.

58. Heinzel FP, Schoenhaut DS, Rerko RM Rosser LE \& Gately MK (1993). Recombinant interleukin 12 cures mice infected with Leishmania major. Journal of Experimental Medicine, 177: 1505-1509.

59. Scharton TM \& Scott $P$ (1993). Natural killer cells are a source of IFN- $\gamma$ that drives differentiation of $\mathrm{CD} 4+\mathrm{T}$ cell subsets and induces early resistance to Leishmania major in mice. Journal of Experimental Medicine, 178: 567-577.

60. Scharton-Kersten T, Afonso LCC Wysocka M, Trinchieri G \& Scott P (1995). $\mathrm{IL}-12$ is required for natural killer cell activation and subsequent $\mathrm{T}$ helper 1 cell de- 
velopment in experimental leishmaniasis. Journal of Immunology, 154: 5320-5330.

61. Murray HW \& Hariprashad J (1995). Interleukin 12 is effective treatment for an established systemic intracellular infection: experimental visceral leishmaniasis. Journal of Experimental Medicine, 181: 387-391.

62. Heinzel FP, Rerko RM, Ahmed $F$ \& Pearlman E (1995). Endogenous interleukin-12 (IL-12) is required for control of Th2 CD4+ $T$ cell responses capable of exacerbating leishmaniasis in normally resistant C57BL/6 mice. Journal of Immunology, 155: 730-739.

63. Hsieh CS, Macatonia SE, O'Garra A \& Murphy KM (1995). T cell genetic background determines default $\mathrm{T}$ helper phenotype development in vitro. Journal of Experimental Medicine, 181: 713-721.

64. Gazzinelli RT, Hakim FT, Hieny S, Shearer GM \& Sher A (1991). Synergistic role of $\mathrm{CD}^{+}{ }^{+}$and $\mathrm{CD}^{+}+\mathrm{T}$ lymphocytes in IFN- $\gamma$ production and protective immunity induced by an attenuated Toxoplasma gondii vaccine. Journal of Immunology, 146: 286-292.

65. Gazzinelli RT, Xu Y, Hieny S, Cheever A \& Sher A (1992). Simultaneous depletion of $\mathrm{CD}^{+}$and $\mathrm{CD}^{+}{ }^{+}$lymphocytes is required to reactivate chronic infection with Toxoplasma gondii. Journal of Immunology, 149: 175-180.

66. Krishnan L, Guilbert LJ, Russell AS, Wegmann TG, Mosmann T \& Belosevic $M$ (1996). Pregnancy impairs resistance of C57BL/6 mice to Leishmania major infection and causes decreased antigenspecific IFN- $\gamma$ responses and increased production of helper 2 cytokines. Journal of Immunology, 156: 644-652.

67. Miller MD \& Krangel MS (1992). Biology and biochemistry of the chemokines: a family of chemotactic and inflammatory cytokines. Critical Reviews in Immunology, 12: 17-46.

68. Kelvin DJ, Michiel DF, Johnston JA, Lloyd AR, Sprenger $H$, Oppenheim JJ \& Wang JM (1993). Chemokines and serpentines: the molecular biology of chemokine receptors. Journal of Leukocyte Biology, 54: 604-612.

69. Baggiolini M \& Dahinden CA (1994). CC chemokines in allergic inflammation. $/ \mathrm{m}$ munology Today, 15: 127-133.

70. Murphy PM (1994). The molecular biology of leukocyte chemoattractant receptors. Annual Review of Immunology, 12: 593-633.

71. Aliberti JCS, Ferreira LRP, Talvani A, Farber J, Silva JS \& Gazzinelli RT (1996). The intracellular protozoa Trypanosoma cruzi and Toxoplasma gondii induce the expression of multiple chemokines by inflammatory murine macrophages. XXI Reunião Anual da Sociedade Brasileira de Imunologia, 1: 93 (Abstract).

72. Amichay D, Gazzinelli RT, Karupiah G, Moench T, Sher A \& Farber J (1996). The genes for chemokines MuMig and $\mathrm{Crg}-2$ are induced in protozoan and viral infections in response to IFN- $\gamma$ with patterns of tissue expression that suggest nonredundant roles in vivo. Journal of Immunology, 157: 4511-4520.

73. Talvani A, Murta S, Soares S, Michailowski V, Aliberti JS, Farber J, Amichay D, Romanha AJ \& Gazzinelli RT (1996). Chemokine expression during experimental Chagas' disease. XXI Reunião Anual da Sociedade Brasileira de Imunologia , 1: 106 (Abstract).

74. Badolato R, Sacks D, Savoia D \& Musso $T$ (1996). Leishmania major: infection of human monocytes induces expression of IL8 and MCAF. Experimental Parasitology, 82: 21-26.

75. Racoosin EL \& Beverley SM (1997). Leishmania major: promastigotes induce expression of a subset of chemokine genes in murine macrophages. Experimental Parasitology, 85: 283-295.

76. Fiorentino DF, Zlotnik A, Mosmann TR, Howard M \& O'Garra A (1991). IL-10 inhibits cytokine production by activated macrophages. Journal of Immunology, 147: 3815-3822.

77. Gazzinelli RT, Oswald IP, James S \& Sher A (1992). IL-10 inhibits parasite killing and nitrogen oxide production by IFN- $\gamma$ activated macrophages. Journal of Immunology, 148: 1792-1796.

78. Oswald IP, Gazzinelli RT, Sher A \& James SL (1992). IL-10 synergizes with IL-4 and transforming growth factor- $\beta$ to inhibit macrophage cytotoxic activity. Journal of Immunology, 148: 3578-3582.

79. Reed SG, Brownell CE, Russo DM, Silva JS, Grabstein KH \& Morrissey PJ (1994). IL-10 mediates susceptibility to Trypanosoma cruzi infection. Journal of Immunology, 153: 3135-3140.

80. Abrahamsohn IA \& Coffman RL (1996). Trypanosoma cruzi: IL-10, TNF, IFN- $\gamma$, and IL-12 regulate innate and acquired immunity to infection. Experimental Parasitology, 84: 231-244.

81. Gazzinelli RT, Wysocka M, Hieny $S$, Scharton-Kersten T, Cheever A, Kühn R, Müller W, Trinchieri G \& Sher A (1996). In the absence of endogenous IL-10 mice acutely infected with Toxoplasma gondii succumb to a lethal immune response dependent on CD4+ T cells and accompa- nied by overproduction of IL-12, IFN- $\gamma$, and TNF- $\alpha$. Journal of Immunology, 157: 798-805.

82. Gately MK, Warrier RR, Honasoge S, Carvajal DM, Farherty DA, Connaughton SE, Anderson TD, Sarmiento U, Hubbard BR \& Murphy M (1994). Administration of recombinant IL-12 to normal mice enhances cytolytic lymphocyte activity and induces production of IFN- $\gamma$ in vivo. International Immunology, 6: 157-167.

83. Silva SJ, Twardzik DR \& Reed SG (1991). Regulation of Trypanosoma cruzi infections in vitro and in vivo by transforming growth factor-ß (TGF-ß). Journal of Experimental Medicine, 174: 539-545.

84. Barral A, Barral-Netto M, Yong EC Brownell CE, Twardzik DR \& Reed SG (1993). Transforming growth factor- $\beta$ as a virulence mechanism for Leishmania braziliensis. Proceedings of the National Academy of Sciences, USA, 90: 3442-3446.

85. Barral-Netto $M$, Barral $A$, Brownell $C E$, Skeiky YAW, Ellingsworth LR, Twardzik DR \& Reed SG (1992). Transforming growth factor-ß in leishmanial infection: a parasite escape mechanism. Science, 257: 545-548.

86. Liew FY, Millott S, Li Y, Lelchuk R, Chan WL \& Ziltener H (1989). Macrophage activation by interferon-gamma from host-protective $T$ cells is inhibited by interleukin (IL)3 and IL4 produced by disease-promoting $T$ cells in leishmaniasis. European Journal of Immunology, 19: 1227-1232.

87. Roberts $\mathrm{CW}$, Ferguson DJ, Jebbari $\mathrm{H}$, Satoskar A, Bluethmann $\mathrm{H}$ \& Alexander J (1996). Different roles for interleukin-4 during the course of Toxoplasma gondii infection. Infection and Immunity, 64: 897-904.

88. James S (1995). Role of nitric oxide in parasitic infections. Microbiological Reviews, 59: 533-547.

89. Moore KJ \& Matlashewski G (1994). Intracellular infection by Leishmania donovaniinhibits macrophage apoptosis. Journal of Immunology, 152: 2930-2937.

90. Lopes MF, Veiga VF, Santos AR, Fonseca MEF \& DosReis GA (1995). Activationinduced $\mathrm{CD} 4^{+} \mathrm{T}$ cell death by apoptosis in experimental Chagas' disease. Journal of Immunology, 154: 744-752.

91. Martins GA, Cardoso MGA, Aliberti JCS \& Silva JS (1995). Modulation of apoptosis cell death by nitric oxide in Trypanosoma cruzi infected mice. Memórias do Instituto Oswaldo Cruz, 90 (Suppl): 171 (Abstract).

92. Candolfi $E$, Hunter CA \& Remington JS (1994). Mitogen and antigen specific pro- 
liferation of $T$ cells in murine toxoplasmosis is inhibited by reactive nitrogen intermediates. Infection and Immunity, 62: 1995-2001.

93. Hayashi S, Chan CC, Gazzinelli RT \& Roberge FG (1996). Contribution of nitric oxide to the host parasite equilibrium in toxoplasmosis. Journal of Immunology, 156: 1476-1481.

94. Scharton-Kersten T, Yap G \& Sher A (1997). Inducible nitric oxide synthase knockout mice are susceptible to chronic but not acute infection with avirulent strain of Toxoplasma gondii. Journal of Experimental Medicine, 185: 1261-1273.

95. Green SJ, Meltzer MS, Hibbs JB \& Nacy CA (1990). Activated macrophages destroy Leishmania major amastigotes by an L-arginine dependent killing mechanism. Journal of Immunology, 144: 278-283.

96. Liew FY, Millott S, Parkinson C, Palmer RMJ \& Moncada S (1990). Macrophage killing of Leishmania parasite in vivo is mediated by nitric oxide from L-arginine. Journal of Immunology, 144: 4794-4797.

97. Wei XQ, Charles IG, Smith A, Ure J, Feng G, Huang F, Xu D, Muller W, Moncada S \& Liew FY (1995). Altered immune responses in mice lacking inducible nitric oxide synthase. Nature, 375: 408-411.
98. Schofield L \& Hackett F (1993). Signal transduction in host cells by a glycosylphosphatidylinositol toxin of malaria parasites. Journal of Experimental Medicine, 177: 145-153.

99. Schofield L, Novakovic S, Gerold P, Schwarz RT, McConville MJ \& Tachado SD (1996). Glycosylphosphatidylinositol toxin of Plasmodium up-regulates intercellular adhesion molecule-1, vascular cell adhesion molecule-1 and E-selectin expression in vascular endothelium cells and increases leukocyte and parasite cytoadherence via tyrosine kinase-dependent signal transduction. Journal of Immunology, 156: 1886-1896.

100. Tachado SD, Gerold P, McConville MJ, Baldwin T, Quilici B, Schwarz RT \& Schofield L (1996). Glycosylphosphatidylinositol toxin of Plasmodium induces nitric oxide synthase expression in macrophages and vascular endothelium cells by a protein tyrosine kinase-dependent and protein kinase C-dependent signaling pathway. Journal of Immunology, 156: 1897-1907.

101. Tachado SD \& Schofield L (1994). Glycosylphosphatidylinositol toxin of Trypanosoma brucei regulates IL-1 $\beta$ and TNF- $\alpha$ expression in macrophages by protein tyrosine kinase mediated signal transduc- tion. Biochemical and Biophysical Research Communications, 205: 984-991.

102. Reiner NE, Winnie NG, Wilson CB, McMaster WR \& Burchett S (1990). Modulation of in vitro monocyte responses to Leishmania donovani. Journal of Clinical Investigation, 85: 19141924.

103. Descoteaux A, Turco SJ, Sacks DL \& Matlashewski G (1991). Leishmania donovani lipophosphoglycan selectively inhibits signal transduction in macrophages. Journal of Immunology, 146: 27472753.

104. Frankenburg S, Leibovici V, Mansbach N, Turco SJ \& Rosen G (1990). Effects of glycolipids of Leishmania parasites on human monocyte activity. Inhibition by lipophosphoglycan. Journal of Immunology, 145: 4284-4289.

105. Hatzigeorgiou DE, Geng J, Zhu B, Zhang Y, Liu K, Rom WN, Fenton MJ, Turco SJ \& Ho JL (1996). Lipophosphoglycan from Leishmania suppresses agonist-induced interleukin $1 ß$ gene expression in human monocytes via a unique promoter sequence. Proceedings of the National Academy of Sciences, USA, 93: 1470814713. 